\title{
EXPERIÊNCIAS DE SI: A POESIA E A NARRATIVA COMO ESTRATÉGIAS PEDAGÓGICAS NA EDUCAÇÃO FÍSICA ESCOLAR
}

Claudio Marques Mandarino*

\section{RESUMO}

Este ensaio tem por objetivo refletir sobre a Educação Física escolar. A partir da ideia da experiência de si consigo mesmo de Jorge Larrosa, é examinada a liberdade de pensamento de escolares. As poesias e as narrativas permitem duas estratégias para que as questões morais e éticas, no sentido foucaultiano, sejam exploradas.

Palavras-chave: Educação Física. Escola. Experiências de si consigo mesmo. Poesia.

\section{INICIANDO OS CAMINHOS}

O que é possível desvelar numa estratégia pedagógica entre a poesia e o diálogo na Educação Física escolar e os relatos orais e escritos de escolares? Inicio este ensaio com esta provocação, pois a mesma emerge a partir de um acontecimento histórico e contingente do cotidiano de uma escola pública municipal de Porto Alegre, com alunos/as de três turmas (totalidades finais 4, 5 e 6) matriculados/as no sistema de Educação de Jovens e Adultos. Num primeiro momento, isso pode remeter a um estranhamento face à inexistência da aproximação dessa área de conhecimento (Educação Física) com a poesia. Com a pergunta, não pretendo apenas procurar uma pedagogia entre a Educação Física e o discurso; isso parece uma redundância. A questão em suspeito é que algo a mais acontece nessa relação causal no momento em que os escolares são colocados em situações de uma prática de liberdade, do dizer verdadeiro e confessional (FOUCAULT, 2006a). O discurso posiciona ao mesmo tempo em que é posicionado, tendo como pano de fundo a disciplina de origem e aquilo que as poesias e narrativas significam e são significadas nesse contexto.

Trazer um elemento da literatura, com seus signos e suas regras dentro do campo epistemológico da Educação Física, representa certo ineditismo quando se volta à sua prática pedagógica. $O$ mesmo se pode dizer quando se trata do contexto escolar. Tanto o professor como os escolares não têm explorado essa contemplação das Culturas Corporais de Movimento Humano (CCMH).

Este ensaio olhou para a poesia e as narrativas como linguagens e discursos a serem explorados nas práticas pedagógicas. Para isso, seguindo a direção de Larrosa (1994, p. 136), a condição é de que "sejam práticas pedagógicas, nas quais o importante não é que se aprenda algo exterior, um corpo de conhecimentos, mas que se elabore ou reelabore alguma forma de relação reflexiva do educando consigo mesmo". Posteriormente, o autor aponta: 
O sujeito pedagógico, ou se quisermos, a produção pedagógica dos sujeitos, já não é analisada apenas do ponto de vista da "objetivação", mas também, e fundamentalmente, do ponto de vista da "subjetivação". Isto é, do ponto de vista de como as práticas pedagógicas constituem e medeiam certas relações determinadas da pessoa consigo mesma. Aqui, os sujeitos não são posicionados como objetos silenciosos, mas como sujeitos falantes; não como objetos examinados, mas como sujeitos confessantes, não em relação a uma verdade sobre si mesmos que lhes é imposta de fora, mas em relação a uma verdade sobre si mesmos que eles mesmos devem contribuir ativamente para produzir. (ibidem, p. 54-55).

Larrosa comenta a questão da Experiência de Si Consigo Mesmo (ESC) entendida como um processo de fabricação de si mesmo e explica:

A experiência de si, historicamente constituída, é aquilo a respeito do qual o sujeito se oferece seu próprio ser quando se observa, se decifra, se interpreta, se descreve, se julga, se narra, se domina, quando faz determinadas coisas consigo mesmo, etc. [...]

A experiência de si, em suma, pode ser analisada em sua constituição histórica, em sua singularidade e em sua contingência, a partir de uma arqueologia de problematizações e de uma pedagogia de práticas de si. E o que aparece agora como "peculiar", como histórico e contingente, não são apenas as ideias e comportamentos, mas o ser mesmo do sujeito, a ontologia mesma do eu ou da pessoa humana na qual nos reconhecemos no que somos. (LARROSA, 1994, p. 43).

Jorge Larrosa, na esteira dos estudos de Michel Foucault sobre as questões morais e éticas, nos empresta uma possibilidade para entender que as poesias e as narrativas são duas estratégias pedagógicas para tratar dessas questões no âmbito escolar a partir das aulas de Educação Física. Foucault (2006a) comenta que na constituição de si do sujeito como moral estão presentes modos de subjetivação e práticas de si para agir sobre si mesmo, conhecendo-se, controlando-se, transformando-se, pondo-se à prova a partir de códigos de comportamentos que não se dissociam entre si. Sobre isso, o filósofo esclarece:

Em suma, para ser dita "moral" uma ação não deve se reduzir a um ato ou a uma série de atos conforme uma regra, lei ou valor. É verdade que toda ação moral comporta uma relação ao real ou que se efetua a uma relação no código a que se refere, mas ela implica também uma certa relação a si; essa relação não é simplesmente "consciência de si, mas constituição de si enquanto "sujeito moral", na qual o indivíduo circunscreve a parte dele mesmo que constitui o objeto desta prática moral, define a sua posição em relação ao preceito que respeita, estabelece para si um certo modo de ser que valerá como realização dele mesmo, e, para tal, age sobre si mesmo, procura conhecer-se, controlar-se, põe-se à prova, aperfeiçoa-se, transforma-se. (ibidem, p. 28).

O desafio que está posto neste trabalho estabelece um viés entre as poesias e as narrativas e a relação que se estabelece com as práticas de si no sentido moral e ético. Para isso, o investimento foi de mostrar como essas linguagens são pedagogizadas e permitem explorar uma liberdade de pensamento que emerge da própria situação vivenciada nas aulas e que se produzem no cotidiano. 
Este ensaio surge a partir das minhas experiências com a Educação Física (EFI) numa escola da rede municipal de ensino de Porto Alegre (EPA). No ano de 2010, constitui um cotidiano das práticas pedagógicas a partir do Projeto Experiências de Si (PES). Seu objetivo foi ressignificar as aulas e oportunizar aos estudantes uma possibilidade de fazerem reflexões sobre si mesmos. As três turmas tinham um encontro de 45 minutos nas terças-feiras, no turno da tarde. Apresentava-se o vídeo e as fotos dos escolares registradas na aula de EFI da semana anterior. Antes de iniciar a aula, era lida e depois entregue para cada estudante uma prosa poética ${ }^{1}$ sobre a última aula de EFI, como é apresentado no fragmento a seguir:

Os tênis e as suas façanhas. Tênis esquecidos, que descansam até que o seu odor sinta saudade do drible fantástico, do cheiro de gol, da alegria do elástico, da memória de sua façanha sendo contada com os risos autoavaliativos da experiência de si [...].

Durante a apresentação, estabeleciam-se diálogos sobre as imagens e os comentários eram guardados num gravador mp3. Essa estratégia permitiu que fossem acumuladas muitas informações que se referiam ao contexto das aulas de EFI. Experiências relacionadas ao contexto da escola em que se faz presente a formação docente são localizadas por Molina Neto e Molina (2009) como importantes iniciativas individuais dos/as professores/as, pois existem espaços de autonomia pedagógica e reflexão propostas pelas unidades educacionais em que há a liberdade de articular, propor e executar inovações pedagógicas. É importante destacar que, no seu cotidiano, muitos/as dos/as professores/as deixam de perceber a sua potencialidade, como nos mostra a pesquisa de Machado et al. (2010), em que abordam o desinvestimento pedagógico na Educação Física escolar através de um estudo de caso. Ao não pedagogizarem as $\mathrm{CMMH}$, os professores correm o risco de ficar num debate tautológico em relação às análises técnicas esportivas, como aparece de forma implícita no estudo de Rodrigues e Darido (2008).

Assim, é importante destacar que o PES amarrou leituras e compreensões em que essa iniciativa não ficasse refém dos arrastões pedagógicos ${ }^{2}$. Foi uma proposta aprovada pela direção da EPA e incentivada pela coordenação pedagógica, sendo que, durante o ano letivo de 2010, foi debatida em diversas instâncias internas do currículo escolar.

Nessa visibilidade sobre a disciplina da EFI, o currículo que emerge se aproxima daquilo que Silva (2005) chama de currículo como uma narrativa, sendo reconhecido pelas múltiplas possibilidades de não se tornar hegemônico e dominante, com as suas formas de contar histórias e produzir identidades e subjetividades, sendo entendidas como textos abertos, histórias que podem ser invertidas, subvertidas, plurais e de oposição. Nesse sentido, o autor mostra que as narrativas se constituem como práticas de significação, nas quais outras coisas podem ser exploradas quan-

\footnotetext{
${ }^{1}$ Total de 33 prosas poéticas nos dois semestres.

${ }^{2}$ Termo utilizado por Molina e Molina Neto quando os gestores públicos oferecem cursos de formação aos docentes das redes de ensino.
} 
do os escolares vivenciam uma prática esportiva com as características históricas e contingentes do seu contexto.

No interior do PES, ou seja, na sala de aula, muitas reações dos escolares apareceram. No seu início, perceberam-se estranhamentos, curiosidades, deboches, atenção, desconsideração, resistência (alguns alunos recusavam-se a guardar a prosa poética nos seus cadernos), entre outros. Esse foi um procedimento em que era possível retirar comentários, risos, avaliações e julgamentos morais de uma forma espontânea. Mais adiante, foi solicitado que escrevessem uma situação da prática desportiva que gostariam de relatar. Juntamente com as poesias escritas (Futebol ao pôr-do-sol e Assim é futebol - Aluna 1), isso foi colocado no mural da PES. Neira (2007, p. 27), ao exemplificar uma experiência do voleibol no currículo escolar, apresenta uma análise que se aproxima daquilo que foi desenvolvido: "Nessa direção, outros textos verbais ou não verbais, como narrativa, filmes, fotos, reportagens etc., podem ser utilizados para proporcionar uma leitura ampla dos contextos culturais tematizados".

Nesse sentido, o autor mostra o valor que textos verbais e não verbais possuem enquanto estratégia de ensino na Educação Física. Isso foi importante, pois a tradição cultural da escola tinha no futsal o seu conteúdo principal, já que essa demanda era trazida pelos/as alunos/as e a sua compreensão sobre aquilo que caracteriza esse momento escolar. Assim, foram negociados com os escolares outros dois esportes coletivos com bola: o voleibol e o basquetebol. No primeiro semestre, aconteceram o futsal e o voleibol, e, no segundo, o futsal e o basquetebol. Ambos eram intercalados semanalmente.

Nesse quadro de realidade apresentado, já é possível imaginar as múltiplas possibilidades para explorar esse cotidiano escolar. Ao tratar da participação daqueles que estão diretamente envolvidos em atividades coletivas, Larrosa (1994, p. 45) comenta:

\footnotetext{
Qualquer prática social implica que os participantes tratem os outros participantes e a si mesmos de um modo particular. Quem são os participantes para si mesmos e quem é cada um para os outros é essencial à natureza mesma de qualquer prática social. Portanto, aprender a participar em uma prática social qualquer (um jogo de futebol, uma assembleia, um ritual religioso etc.) é, ao mesmo tempo, aprender o que significa ser um participante. Aprendendo as regras e o significado do jogo, a pessoa aprende ao mesmo tempo a ser um jogador e o que ser um jogador significa.
}

Aos escolares era oferecida a possibilidade de narrarem-se, avaliarem-se, compararem-se, ou seja, fazerem coisas consigo mesmos. Essa problematização permitiu uma reflexão em relação à questão moral e um entendimento do que significava ser um participante da aula.

Mais do que valorizar conteúdos previamente estabelecidos ou verdades já dadas, faz-se presente uma liberdade pedagógica que o professor deve utilizar quando pretende ousar no seu cotidiano.

\section{O INTERIOR DAS EXPERIÊNCIAS DE SI CONSIGO MESMO}


Nesta seção, serão apresentados recortes que mostram fragmentos dos/as escolares no PES. As poesias e as narrativas que trazem mostram algumas movimentações que fizeram a partir de seus discursos e o quanto os temas que abordaram de alguma forma os posicionam como sujeitos de determinados modos de subjetivação. Durante um bom tempo, os/as alunos/as dessa escola foram narrados como em situação de rua. Suas histórias individuais, entre outros aspectos, falavam de contextos de vida nos quais os vínculos familiares foram desfeitos e suas experiências de vida passavam longe das tradicionais capturas das práticas de si na modernidade, ou seja, pela família, pela escola, pela igreja etc. Como esse perfil de escolares ainda predomina, isso não pode ser desconsiderado quando o relaciono às estratégias pedagógicas aqui apresentadas. No período em que aconteceu essa experiência, alguns escolares eram deixados pelos pais de carro ou utilizavam ônibus para chegar na escola; também se deslocavam de suas residências familiares e ainda se faziam presentes aqueles que dormiam na rua, em abrigos municipais, na vila próxima à escola ou em mocós. Sem a pretensão de marcar uma identidade fixa e permanente, é importante destacar que a experiência acontece dentro de uma multiplicidade de lugares em constante conflito nas pedagogias de si, tal como explica Gallo (2006, p. 184) na esteira foucaultiana, de que "é preciso adestrar a si mesmo para que seja possível viver; é preciso adestrar o pensamento, e a escrita é tomada como uma forma de produzir tal adestramento, na mesma medida em que o indivíduo se conhece e cuida de si".

Larrosa (1994), ao comentar sobre a estrutura da linguagem e o seu expressar-se, explica que o discurso funciona de forma inseparável daquele que o produz, onde estão as práticas sociais em que se fala e se faz falar, como uma máquina de visibilidade e dizibilidade. A seguir, é apresentada uma poesia para iniciar essa interpretação:

\begin{abstract}
Assim é futebol. Todo futebol começa com muita energia/ A adrenalina do jogo contagia/ Futebol sem bola não é nada/ Futebol na mente e nos pés do jogador/ Futebol é a vontade de ser um vencedor/ A câmera filma a galera sorridente/ Filma o detalhe do passe surpreendente/ Chutes, dribles, passes e repasses no compasso/ A bola rala e rola na quadra/ De um lado para outro é jogada, sem descansar/ Na tentativa de realizar o gol de quem/ quer jogar. (Aluna 1).
\end{abstract}

Passados quatro meses nesse recorte temporal, desde março até junho, ao explorar a contemplação da aula de Educação Física, a aluna se posiciona num lugar de quem enxerga um espelho e os seus reflexos como expectadora e participante. Palavras como energia, vencedor, sorriso, dribles, quadra, gol, jogo e jogada juntam-se na poesia da Aluna 1 para retratar o seu olhar sobre esse quadro que a subjetiva, que mostra como ela deve se comportar como um membro que pratica esse esporte. Inclusive ela comentou que nessa segunda poesia tinha retirado os versos muito infantis contidos na primeira, em abril ("Com o grupo reunido/ o time é definido/ alguns levam na brincadeira/ e tudo é besteira/ Começa o jogo, bate forte o coração/ E toda a gurizada, é só animação/..."). Ao ser indagada sobre o que escreveu, comentou que continuou com vontade de escrever mais poesias, pois na escola mui- 
tos/as professores/as elogiaram a sua iniciativa. Nas palavras da estudante, foi dito: "Eu continuei escrevendo mais poesias, porque todo mundo elogiou a primeira poesia que escrevi. Se tivessem criticado, não iria mais escrever nenhuma poesia". Não bastava somente escrever uma poesia, ela tinha que se perceber num discurso em que um poeta é posicionado no seu reconhecimento. E um reconhecimento que mostrava que ela já não era a mesma aluna da primeira poesia. De alguma forma ela tinha transformado o seu pensamento em relação ao ato de escrever poesias. Esse é processo de valoração dado por ela, em que sua observação está imbuída de reflexão, que permite narrar a si mesma em relação aos sentidos daquilo que potencializou, posteriormente, o seu olhar em relação ao cotidiano escolar e à vontade de escrever. Ela disse que levou mais de duas horas escolhendo as palavras que rimassem. Esse foi o primeiro movimento de uma aluna ${ }^{3}$ que permitiu com que outras formas de se expressar aparecessem, quando escreveu sobre uma situação vivenciada na aula de voleibol:

Gostei quando, durante uma aula de Educação Física, estávamos jogando vôlei, aí eu defendi uma bola que parecia que ia para fora, mas eu acreditei nela, e defendi com uma manchete, passei para o Caco, que fez ponto para a nossa equipe. Estou jogando muito melhor do que antes, acho que fica mais difícil jogar seguindo as regras do jogo, mas é melhor, embora eu sempre tenha jogado por diversão. (Aluna 1).

Essa avaliação da Aluna 1, sobre como é exigida e como gostaria de jogar, caminha na direção daquilo que Neira (2007) comentou na experiência sobre o voleibol para elaborar atividades didáticas, disponibilizando momentos de contemplação. A autoavaliação sobre a sua aprendizagem, juntamente com a moralidade do jogo, suas regras e como se posiciona frente a ele, mesmo que seja "por diversão", aproxima-se do que Larrosa (1994) abordou, sobre o que significa ser um jogador dentro de um grupo. Juntamente a isso, o relato escrito mostra o quanto o esporte está mostrando o quanto ela se transformando, deixando ser a mesma aluna que no está apta para esta CCMH registrando, portanto, uma ESC a partir do que se tem vivenciado nessa prática. Mas esse é apenas um dos inúmeros conhecimentos que são debatidos no PES.

Continuando com a mesma aluna, num outro momento surgiu um tema relacionado ao período da ditadura militar no Brasil e no Chile, quando perguntou sobre a imagem que aparecia no fundo da tela do computador. Expliquei que se tratava do Museo de La Memoria y los Derechos Humanos, em Santiago/Chile. Nesse momento, foi explicado que naquele lugar se encontravam muitos registros da ditadura militar de Augusto Pinochet, em que apareciam muitas imagens, reportagens e relatos sobre o golpe militar, a tortura, a privação de liberdade, resistência etc., ocorridos entre os anos de 1973 e 1990. Um tempo depois, a aluna escreveu no seu blog, que tratava do projeto sobre democracia, uma poesia que foi lida no Sarau de Poesias ${ }^{4}$ :

\footnotetext{
${ }^{3}$ Todos os registros que serão apresentados terão como critério a não modificação da forma como foram escritos originalmente pelos/as escolares.

${ }^{4}$ Essa poesia é fruto da passagem da aluna também pelo projeto das disciplinas de Geografia e Espanhol, intitulado Pasos del Che, bem como da disciplina de Literatura e Língua Portuguesa.
} 
Ditadura Militar. A duras penas fez-se a ditadura/ Para todos foi imposta a censura/ Queriam calar o povo brasileiro/ Mas como calar um povo tão guerreiro?/ Na política não havia coerência/ Ordem e progresso só na aparência/ Aos militares cabia a liderança/ Para o povo restava esperança/ Após luta, revolta e humilhação/ Enfim veio ao povo a libertação. (Aluna 1).

Nesse momento, percebe-se que a estudante não estabelece uma territorialidade nas suas aprendizagens, pois estas se fazem interligadas nos diferentes espaços escolares em que exerce a prática de si. Isso poderia se relacionar como um modo de cuidar de si ao ser aluna dessa escola e o que ser aluna dessa escola envolve no seu próprio entorno social. Uma prática quase que ascética para renunciar outro modo de ser e projetar a sua conclusão no Ensino Fundamental, pois, nesses modos de subjetivação, estava se inscrevendo na própria forma de ser e ter uma relação consigo mesma. Para Foucault (2006b), ao fazer um discurso que se objetiva ser um exercício de si sobre si mesmo, estão presentes o visível e o dizível, o verdadeiro e o falso. As narrativas que aparecem quando ela observa a si própria em vídeos e fotos permitiram que estivessem presentes esses exames e as confissões para contar a sua experiência de estudante, e estudante que, entre outras coisas, aprende a olhar para si mesma, a fazer uma pedagogia de si.

Passando agora para um registro de grupo, lembro de que no dia 7 de outubro comecei a mostrar o vídeo da última aula, e a Aluna 4 me interpelou sobre o fato de não ser oferecido o voleibol nas aulas, pois ela, assim como outras colegas, gostaria de praticar esse esporte. Tal momento foi interessante, pois a adolescente começou a trazer argumentos, tais como: "quando estou na praia, jogo voleibol o dia inteiro". Logo em seguida, perguntou se não tinha professora de Educação Física na escola ou, então, por que não trocar o basquetebol pelo voleibol. Tentei explicar que o conteúdo do voleibol já tinha sido garantido no primeiro semestre. Outros colegas se sensibilizaram com a solicitação que estava sendo feita, e mais uma vez tentei mostrar a coerência da minha proposta e que o futsal também poderia ser substituído pelo voleibol, porque se fez presente nos dois semestres. $O$ interessante foi perceber que a aluna usou de sua liberdade, em que se reconhece como membro de determinada prática da $\mathrm{CCMH}$, para expressar uma insatisfação e que posteriormente a mobilizou para fazer essa resistência ${ }^{5}$ em relação aos combinados com os escolares no segundo semestre. Nesse momento, a atenção para a aula de Educação Física filmada foi perdendo o foco em função das questões morais e éticas que apareciam. Nas falas, começaram a surgir outras ESC em relação às $\mathrm{CCMH}$ referentes ao roller, ao skate, à bicicleta e ao carrinho de rolimã, a caminhar em cima do muro, em que existia uma dose de aventura, pois a aluna começou a comentar sobre situações em que se colocou em risco, acidentando-se e ficando duas semanas com gesso, sem caminhar. Esse deslocamento despertou o interesse de outros colegas que começaram a comentar sobre suas aprendizagens no skate descendo a lomba, que se apoiavam nos ônibus para se deslocar, sofriam acidentes de bicicleta, fratu-

\footnotetext{
${ }^{5}$ Numa das últimas assembleias do semestre, ao ser avaliado "o que precisava melhorar na escola", foi colocado que era preciso ter aulas de voleibol.
} 
ras, ou seja, experiências que envolviam uma transgressão às regras de segurança. Mesmo sendo questionados em relação a isso, os escolares sentiram-se à vontade para narrá-las como se estivessem amparados por um contexto legitimado pela infância e pela juventude. Porém o fato ficou mais localizado num sentido de irresponsabilidade.

Nesses diálogos em que se percebe o/a estudante como um participante que se inclui numa ou em mais modalidades de pertencimento de um grupo, abre-se um leque de possibilidades para o discurso moralizante do educador se faça presente, e o pensamento dos/as estudantes foi capturado para olharem-se nas suas experiências em relação à $\mathrm{CCMH}$. O que aparece aqui são práticas de si nas quais se situam o escrever e o falar, como Foucault (2006b) comenta, quando trata em relação à revelação e às confissões tão presentes nas práticas pastorais, em que os modos de subjetivação entram em jogo. Sobre isso, em algumas passagens sobre a postura do discípulo em relação ao mestre, o autor destaca:

Tem algo a dizer, tem a dizer uma verdade. Mas que verdade é esta que tem ele a dizer, ele, o dirigido, aquele que é conduzido à verdade, que será por outro lado conduzido à verdade? É a verdade de si mesmo [...]. Mas enfim, se tivermos a este respeito uma visão histórica um pouco mais ampla, penso que preciso considerar como um acontecimento de grande importância, nas relações entre sujeito e verdade, o momento em que o dizerverdadeiro sobre si mesmo tornou-se uma condição para a salvação, um princípio fundamental na relação do sujeito consigo mesmo e um elemento necessário ao pertencimento do indivíduo a uma comunidade. (FOUCAULT, 2006b, p. 437).

Como proposta de ensaio, parece que aqui começa a se desdobrar uma categoria de análise em que a confiança dos/as estudantes para expressarem seus pensamentos emerge a partir das estratégias pedagógicas utilizadas. É possível, portanto, investir na noção de jogos da verdade da qual trata Foucault (2006c), ao se referir àquilo que fez pensar a si próprio e refletir sobre si mesmo como sujeito falante - neste caso tratado, pensar a si próprio a partir de sua experiência de si consigo mesmo na Educação Física. Fica aqui um campo a ser investigado posteriormente. Agora, retornando ao foco da Educação Física, a questão das práticas de si ganha potencialidade, pois, numa continuidade, com a possibilidade de expressar suas experiências nas aulas de Educação Física, um escolar fez seguinte o registro:

O lance. Começou numa falia do goleiro, um erro num lance. O Pedro driblô - Celso lá perto e a bola sobrou perto da grande área um toque um tapa uma sutileza de chute lá onde a coruja mora como os peladeiros falam lá no "v" ou na gaveta. Bateu na trave/ e entro um golaço. A Tatiana nem viu a cor da bola. O Fred sai da frente numa ameaçada bola, o lance que me realizou. (Aluno 4).

Um "golaço" se inscreve numa verdade daquilo que a façanha de um gol pode ser traduzida e na possibilidade daquilo em que o si mesmo se constitui numa experiência desse gesto - um gesto carregado de cultura, habilidade, emoção, entre outros - que o seu corpo é capaz de fazer, sentir e ser testado. Mas isso só é possível de acontecer no momento em que existe uma negociação com a sua inserção em tal 
prática social. É uma negociação que ensina a ser um participante desse esporte. Nessa mesma linha de raciocínio, outro aluno comentou o seguinte:

Eu gostei do meu grupo do meu time porque nós fazíamos algumas jogadas. A nossa estratégia era deixar fazer um gol porque eles se exibiam chamando de perdedor e depois nós fizemos um ataque surpresa. (Aluno 5).

Aqui, não importa como o gol foi feito, mas o seu acontecimento, fruto de uma estratégia coletiva. Para encaminhar o final desta seção, serão apresentadas algumas avaliações feitas pelos/as escolares, bem como a última poesia escrita:

Eu achei muito criativo para mim por que deu para mim ver os meus erros e as palavras que eu falava. Eu aprendi muito no vôlei como se dava manchete saque e o bloqueio é isso. (Aluno 7).

Futebol - eu achei muito legal o futebol coletivo apesar de ter uns que jogam individualmente mas é legal jogar bola na física. Vôlei - o vôlei foi legal para nós todos tanto para a meninas e o guris. Filmagem - a filmagem é boa para nós corregir o nosso erro e também para nós ver os momentos bom e ruim. Ex. gol falta sofrida, palavrões mais no final o jogo e da tudo certo. Poesia - a poesia é aparte que eu mais gosto da aula de física são umas poesias muito boas. (Aluno 6).

As avaliações desses dois alunos trazem recortes daquilo que o PES conseguiu explorar em relação a uma possibilidade de poder olhar para si, narrar-se, avaliar-se - e, ao mesmo tempo em que narram e avaliam, mostram a possibilidade de inscreverem-se num discurso moral. A poesia que o aluno comenta se refere às leituras feitas em sala de aula e que os levavam a refletir sobre a aula anterior. Uma interpretação que faço é que a liberdade que os/as escolares estabelecem, para se expressarem pelas poesias e narrativas orais e escritas, deve-se ao fato de minha posição de professor fazer uma escrita de si. Ao mesmo tempo em que posicionava os/as estudantes como sujeitos falantes, exercia o mesmo exercício quando escrevia e entregava as poesias, ou então dialogava sobre os registros da aula anterior. Aconteceu uma situação em que, ao chegar à escola, um aluno me abordou, dizendo: "Professor, eu fiz um gol hoje pela manhã". Isso era interpretado como um presente que estava sendo dado, pois vinha seguido de uma escolha para quem deveria ser contato, bem como os detalhes que acompanhavam essa experiência de si.

O mesmo aluno que fez esse movimento no qual mostrava essa reflexão sobre o que está presente na sua formação foi quem escreveu e leu a última poesia do semestre:

No momento certo/ Mando papo reto/ Escola Porto Alegre/ É o lugar certo/ Temos grandes professores/ Nossos companheiros de todas horas/ Seja na quadra de voleibol/ Ou na hora do recreio/ Passamos em muitas salas/ De cerâmica ou de papel/ Na literatura, grande escritura/ Fazendo do passado e da vida dura/ Da história à geografia. (Aluno 3).

Lida durante a sua formatura do Ensino Fundamental, a poesia representa um fechamento de um ano em que o exercício para a sensibilidade esteve presente em diferentes momentos da sua formação escolar. Por outro lado, formar-se mostrava 
como tinha conseguido exercer determinados modos de subjetivação que exigiram algumas renúncias para pensar um projeto de vida diferente daquele que já tinha experimentado. Assim como essa e as outras poesias, juntamente com os demais relatos orais e escritos, todos caminham numa direção em que foi explorada a liberdade de pensamento. Foucault (2006, p. 250) tratar do tudo e do tudo a dizer, ou seja, uma liberdade de quem fala: "[...] a franqueza, a liberdade, a abertura, que fazem com que se dizer o que se tem a dizer, da maneira como se tem vontade de dizer e segundo a forma que crê ser necessário dizer". Nessa linha de raciocínio, fazendo uma relação com as diferentes formas de linguagens expressas pelos/as escolares e analisando a escrita de si tratada por Michael Foucault, Gallo (2006, p. 185) comenta:

As duas formas de escrita que Foucault analisa são os hypómnemata, cadernos em que se recolhiam fragmentos de coisas lidas e ouvidas, de modo a permitir a reflexão posterior e, com isso, a constituição de si mesmo; e as correspondências, nas quais narra-se a si mesmo, na mesma medida em que se transmitem outros conselhos, sugestões, etc. Nos hypómnemata, a escrita é um trabalho sobre si mesmo; nas cartas, além do trabalho sobre si mesmo há também a intenção de afetar o outro, de produzir no outro também um trabalho sobre ele próprio.

Ao fazer a amarração com o currículo e o que foi explorado no PES, recordo Silva (2005), para quem as narrativas se constituem em importantes formas de dar sentidos ao nosso lugar no mundo e ao mesmo tempo nos posicionar frente a ele no momento em que contamos sobre nós mesmos. Os recortes que foram feitos aqui mostram como foi possível explorar a prática pedagógica da Educação Física escolar a partir da estratégia das ESC. O trabalho explorou uma direção da relação feita por Gallo (2006, p. 188) entre o cuidado de si como ser consigo, como um governo de si, e a educação, que nomeou como uma educação menor: "Um jogo em que uns se fazem livres aprendendo da liberdade dos outros; em que uns se fazem livres na medida em que ensinam a liberdade aos outros". Esse é um caminho a ser escolhido para responder à pergunta inicial que acompanhou o ensaio, pois, mais do que trazer respostas, talvez seja necessário pensar nas práticas pedagógicas solitárias que acontecem no interior de uma aula e a forma como se dão as reciprocidades entre professor/a e aluno/a. Nisso está presente um campo muito rico a ser explorado por educadores que pretendem compreender melhor o que estão produzindo no seu fazer pedagógico.

\section{CONSIDERAÇÕES FINAIS}

Como no campo acadêmico da Educação Física escolar existe uma carência de estudos explorando as poesias e as narrativas orais e escritas a partir das experiências de si consigo mesmo, isso restringiu o diálogo com outras produções científicas que poderiam reforçá-las. Nesse sentido, serão destacadas algumas teses que as práticas pedagógicas aqui apresentadas e debatidas podem capturar, oportunizando futuros interesses para essa disciplina. Vamos a elas: 
a) Estratégias que utilizam diferentes formas de expressar a liberdade de pensamento são possibilidades a ser experimentadas, além de exigirem posturas que devam transitar num projeto disciplinar que envolva a escola. Dessa forma, elementos que estão nas emoções, na cultura, nas habilidades, na infância e juventude, no gênero, no esporte e lazer, no trabalho, na criticidade, entre outros - naquilo que se torna parte integrante das relações entre os modos de subjetivação nas práticas de si -, podem ser significados a partir da Educação Física. Encontrar esses tempos pedagógicos na escola faz parte de uma construção curricular que passa pela formação docente e por uma discussão das prioridades e do uso dos tempos escolares.

b) As ESC apresentaram estratégias para explorar pedagogicamente os discursos dos escolares no cotidiano escolar. Nesse sentido, muitos temas pertencentes ao contexto escolar podem surgir num diálogo que ultrapassa as fronteiras disciplinares, apresentando vieses transversais ao conhecimento escolar, promovendo, aí sim, uma melhor compreensão de como se está lidando com gênero, etnia, classe, religiosidade, entre outros. Ao se deparar com cada um desses elementos, professores/as e escolares posicionam-se e são posicionados nas ESC. Os argumentos que movimentam os lugares assumidos estão carregados de enunciados, com suas verdades ou não. $O$ desafio é trazê-las enquanto práticas pedagógicas de significação para compreender o que se produz quando se narra, se avalia, se compara, ou seja, quando se faz coisas consigo mesmo.

c) Dar a voz àqueles muitas vezes esquecidos é como escavar terrenos em que se depositam possibilidades de pesquisas para o cotidiano da Educação Física escolar. Por exemplo, explorar a educação para uma liberdade do pensamento, utilizando como estratégias as poesias, narrativas orais e escritas, abre caminhos nem um pouco conhecidos, seguros ou já percorridos, para que aconteça uma Experiência de Si Consigo Mesmo, em que são produzidos textos de identidades.

\section{REFERÊNCIAS}

FOUCAULT, M. História da sexualidade: o uso dos prazeres. $11^{\stackrel{a}{ }}$ Ed. Rio de Janeiro, Graal: 2006a.

A hermenêutica do sujeito. 2a Ed. Tradução: Márcio Alves da Fonseca; Salma Tannus Muchail. São Paulo: Martins Fontes, 2006b.

Ética, sexualidade, política. Organização e seleção de textos: Manoel Barros da Mota. Tradução: Elisa Monteiro; Inês Autran Dourado Barbosa. 2.ed. Rio de Janeiro: Forense Universitária, 2006c.

GALLO, S. Cuidar de si e cuidar do outro: implicações éticas para a educação dos 
últimos escritos de Foucault. GONDRA, J. KOHAN, W (Orgs.). Foucault 80 anos. Belo Horizonte: Autêntica, 2006. p. 177-189.

MACHADO, T. S. et al. As práticas de desinvestimento pedagógico na Educação Física escolar. Revista Movimento. Porto Alegre, v.12, no 02, p.129-147. Abril/junho de 2010.

MOLINA NETO, V.; MOLINA R. M. K. A prática pedagógica do professorado de Educação Física no cotidiano escolar pesquisar e aprender: megaponto de vista. In: MOLINA NETO V. et al. (Orgs.). Quem aprende? Pesquisa e formação em Educação Física escolar. ljuí: Unijuí, 2009. p. 12-36.

NEIRA, M. G. Ensino da educação física. (Coleção Ideias em Ação/ Coordenadora: Anna Maria Pessoa de Carvalho). São Paulo: Thompson Learning, 2007.

LARROSA, J. Tecnologias do Eu e Educação. In: SILVA, T. T. O sujeito da educação: estudos foucaultianos. Petrópolis: Vozes: 1994.

Pedagogia profana: danças, piruetas e mascaradas. $4^{\mathrm{a}}$ ed. Trad. Alfredo VeigaNeto. Belo Horizonte: Autêntica, 2004.

RODRIGUES, H. A.; DARIDO, S. C. A técnica esportiva em aulas de Educação Física: um olhar sobre as tendências sócio-culturais. Revista Movimento. UFRGS/Esef, 2008. v. 1, n. 2, Maio/agosto.

SILVA, T. T. Currículo e identidade social: territórios contestados. In: JUNIOR, D. M. A. et al. (Orgs.). Alienígenas em sala de aula: uma introdução aos estudos culturais em educação. 5a Ed. Porto Alegre, Vozes, 2005, p. 190-207.

\section{EXPERIENCES IN YOURSELF: THE POETRY AND NARRATIVE AS PEDAGOGICAL STRATE-} GIES IN THE SCHOOL PHYSICAL EDUCATION

\section{ABSTRACT}

The objective of this essay is to reflect about School Physical Education. Is starts from the idea of Jorge Larrosa, the experience in yourself, where it is explored the liberty of students' thoughts. The poetries and narratives allow two strategies that could help us, as said Foucault, to explore moral and ethics questions. 
Keywords: Physical Education. School. Experiences in yourself. Poetry.

EXPERIENCIAS DE SÍ: LA POESÍA Y LA NARRATIVA COMO ESTRATEGIAS PEDAGÓGICAS EN LA EDUCACIÓN FÍSICA DE LA ESCUELA

\section{RESUMEN}

Este ensayo tiene como objetivo hacer una reflección de la Educación Física escolar. Partiendo de la idea de la experiencia de sí consigo mismo de Jorge Larrosa, será explorada la libertad del pensamiento de los estudiantes. Las poesías y las narrativas permiten dos estrategias para que los hechos morales y éticos, de acuerdo con los apuntamientos foucaultianos, sean exploradas.

Palabras-clave: Educación Física. Escuela. Experiencia de si consigo mismo. Poesías.

Endereço para correspondencia: mandarino@unisinos.br 